\title{
ICT-based didactic strategies to build knowledge models in Electronics in Higher Education
}

\author{
C. Sánchez-Azqueta, S. Celma, C. Aldea \\ Aragón Institute of Engineering Research \\ Universidad de Zaragoza \\ Zaragoza, Spain \\ \{csanaz, scelma, caldea\}@unizar.es
}

C. Gimeno

ICTEAM Institute

Université catholique de Louvain

Louvain-la-Neuve, Belgium

cecilia.gimenogasca@uclouvain.be

\author{
E. Cascarosa \\ Didactic of Experimental Sciences \\ Universidad de Zaragoza \\ Zaragoza, Spain \\ ecascano@unizar.es
}

\begin{abstract}
This paper presents a didactic strategy based on information and communication technologies (ICTs) to help students build knowledge mental models in the context of Higher Education. It presents a methodology that combines the flipped classroom with other active methodologies and traditional lessons to improve the teaching/learning process of Electronics in university studies in Physics. Using the flipped classroom as the main strategy, the proposed methodology allows devoting more classroom time to active learning so that the instructor can follow the student learning process and evaluate model construction, while at the same time it increases student implication and fosters autonomy and cooperation with peers, contributing to a better construction of knowledge mental models in Electronics.
\end{abstract}

\section{INTRODUCTION}

One of the main goals of all degrees in Higher Education is that students be able to acquire transverse and specific skills, and to integrate them in the Information and Knowledge Society, which entails promoting those tools that are most adequate to deepen in the main topics of each course, from a point of view where what is learned is as important as how it is learned.

To achieve this, it is essential to design teaching methodologies that are capable to focus on the students, taking into account their own learning characteristics. A skill-based teaching, thus, requires a deep change in the usual conceptions and practices, both by the students and the instructors.

In this respect, Information and Communication Technologies (ICTs) have been showed to be a very suited tool to facilitate, promote and enhance the autonomous learning of the students; besides, they expedite the supervision, guidance and support offered by the instructors [1].

The applications of ICTs that have the most potential for education are those that allow a direct intervention in the stages where students are building their own mental knowledge models, assessing their prior conceptions, sequencing activities towards the construction of the models and increasing the presence of the instructors during the process.

\section{A. Model-based learning}

Gobert and Buckley defined model-based learning as the construction of mental models of phenomena [2], which is achieved integrating information about their structure, function and causal mechanism, and mapping it into analogous systems.
In the classical approach of Gilbert, models are built through induction based on simplified representations of systems [3]. Nowadays, model-based learning is an essential part in the evolution of scientific knowledge and, thus, constitutes an important portion of the strategies in science education.

Following this, many authors today advocate that modelling needs to become a key part of scientific education [4]-[7]. In this respect, it has been shown that the construction of mental models brings along the development of most scientific skills: raise problems, formulate hypotheses, look for information, develop new explanations or interpret phenomena, among others [8], [9]. Nevertheless, it is uncommon in Higher Education to dedicate resources to help students in the construction of their own knowledge mental models [10].

\section{B. The flipped classroom in higher education}

Flipped classroom methodologies are based on the design of specific activities to work outside the classroom so that class time is discharged and can be used to encourage active participation through activities that promote the implementation and application of ideas [11]-[16].

Although there are many patterns to develop flipped classroom activities, the most common are those where students watch pre-posted lectures or read papers and solve exercises before class, freeing classroom time for active learning, which has important intrinsic benefits while allowing a closer monitoring of the learning process of students [17]-[19].

In this respect, the flipped classroom is a relevant instructional strategy because it addresses teaching transferring the work to carry out certain learning processes to outside the classroom, allowing the use of class time for activities that facilitate and enhance other learning processes that focus on practising instead of just listening [20]-[22]. This combination of direct instruction and constructionist method is of great help to direct the model acquisition.

\section{EXPECTATIONS OF THE CURRENT STUDY}

The classical interpretation of model-based learning entails students engaging in an iterative process oriented to build a mental model of a given phenomena. This can be achieved establishing comparisons, integrating information, by inductive processes, assuming simplifications, etc. Nevertheless, despite 


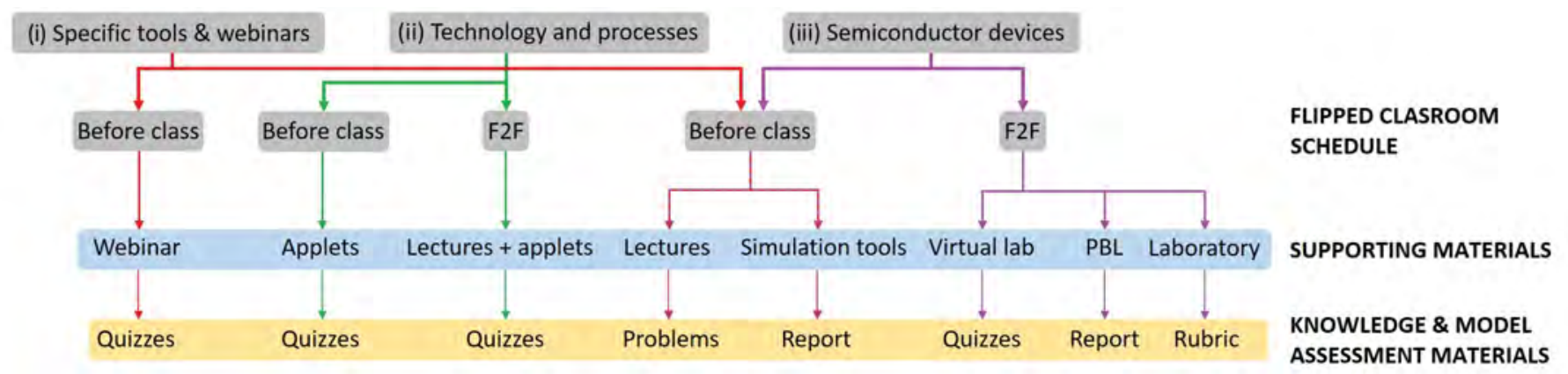

Fig. 1. Diagram showing how the activities to implement the flipped classroom methodology are distributed. The resources presented to students are highlighted in blue, whereas the resources designed to assess the understanding of the topics and the degree of construction of the models are shown in orange.

model-based learning needs to be carried out by the students, the instructors can adopt strategies to facilitate the acquisition of the models and to assess their correctness.

It is in this scenario where the flipped classroom methodology stands out. Flipped classrooms are based on providing the students with activities to carry out outside the classroom, and lectures are devoted to implementing active learning activities aimed at reinforcing what students have learned during the activities carried out outside the classroom.

In this way, by the application of a methodology based on the flipped classroom, the authors expect to contribute to a correct development of mental models by the students. The activities are based on the use of a wide range of learning supporting materials, each of which plays a role in the intended outcome, which is facilitating the construction of mental models by the students. Also, the implementation of the flipped classroom has proven to increase student implication and satisfaction, which relates to a better performance and deeper learning [23].

\section{RESEARCH METHOD}

The strategy entails the design of a series of specific teaching resources available in a virtual learning environment, which is the online platform of the authors' institution, available to the students enrolled in the courses offered by the Electronics Department, both in Bachelor and Master Degrees.

In this work, the participants are students of the course Physical Electronics, taught in the last year of the Degree in Physics. Consequently, they have long and successfully learned various areas of Physics, and have a strong background in mathematical methods and relevant laboratory experience; thus, they are autonomous and can be faced with activities involving less guidance, leaving more space for active learning.

In turn, the course Physical Electronics introduces the basic properties and physical phenomena of electron transport in semiconductors, and uses them to characterize semiconductor devices, build behavioural models and compare to the real operation, and analyse their main applications.

The flipped classroom serves as a pedagogical strategy to help students build their knowledge models, and also to assess the construction. Class time is used to improve, put into context and check the models, and classroom activities are given an innovative approach to promote other skills such as autonomy or multi-directional learning [24].

This work combines two lines of action: (i) before-class and face to face (F2F) class activities based on information and communication technologies (ICTs), some with enhanced content, and (ii) F2F activities to apply the knowledge acquired using active learning strategies [25], [26].

\section{A. Research instruments}

A set of specific teaching resources has been created that can be used before and during class time. They provide an innovative approach to the discussion of models, facilitating the understanding of physical phenomena through a visual description that complements the conventional analytical treatment.

The resources are divided into learning supporting materials and learning and model construction assessment materials. Both categories support the teaching/learning process and its evaluation in the flipped classroom.

1) Learning supporting materials:

- Webinars: Two modules are scheduled: a synchronous, specialized one of two hour-long sessions covering the design and fabrication of microelectronic circuits, and an asynchronous one that gives a realistic view of the industrial processes involved in the fabrication of integrated circuits (ICs).

- Applets: A library of Matlab interactive applications is presented [27] that covers: (i) the fabrication of ICs, (ii) semiconductor physics, and (iii) semiconductor devices [28]. Students can change the parameters that govern the phenomena, improving the understanding of the topics.

- Tutorials and lectures: Tutorials lead students into the most relevant aspects of the tools they use, providing them with working examples. The lectures are designed as standard explanatory sessions where the theoretical foundations of the topics studied in the course are given.

- Simulation tools: Students have access to academic licenses of the Cadence design environment [29]. Also, they are asked to find and use resources available in the Internet and compare them with the professional tools. 

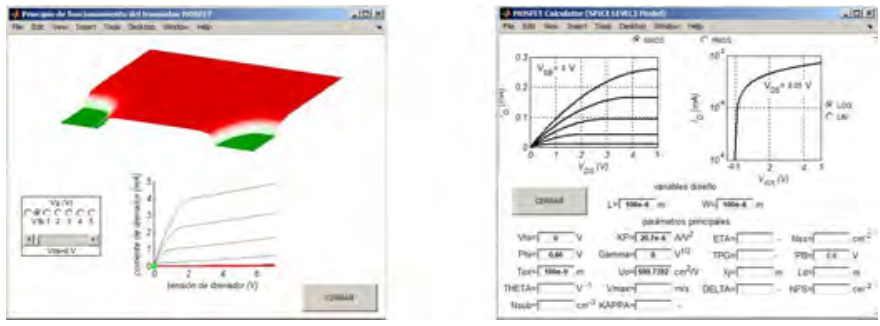

Fig. 2. Illustration of the applet execution for (left) the structure of the MOS transistor and (right) its operation.

- Virtual laboratory: Virtual laboratory sessions on the design and characterization of electronic systems are scheduled.

- Problem-base learning (PBL) sessions: They are designed as a learning activity where students must cooperate with their peers, in groups, with the assistance of the instructors. The problems require not only analyses or derivations, but also higher-order tasks such as proposing designs to meet some requirements.

2) Learning and model constructions assessment materials:

- Quizzes: A set of quizzes is integrated to provide students with feedback about their learning process, fostering their metacognitive skills [30]. Also, the quizzes can be tailored to focus on key aspects in terms of the model construction.

- Problems: They consist of classical academic exercises and problems that students solve on their own, providing valuable training before $\mathrm{PBL}$ sessions. The problems exercise the basic theoretical concepts in different scenarios, which contributes to the construction of the mental models by comparing and integrating information.

- Reports: Their elaboration is relevant because students reflect on their findings within the theoretical framework. Also, they need to be written down in an ordered and clear way, contributing to a reflection on their mental models.

- Wikis: Students develop a wiki on physical devices, collecting and organizing information about their operating principles, electrical characteristics and other parameters of interest [31]. Wikis contribute to model construction because they are a product that results from cooperation and consensus between peers, which means that students need to check and confront their models.

\section{Practical REALIZATION}

The design of integrated circuits represents a very valuable bridge between the scientifically-driven items found in the curriculum of a Degree in Physics and the practical applications that are usually covered in more technologybased programs such as Engineering studies. Therefore, it is important that Physics graduates, besides understanding the physical foundations of the operation of semiconductor devices and integrated circuits, are also familiar with their practical limitations. In other words, there are countless tangible results to which the mental models that the students build from the theoretical descriptions can be compared.

The proposed methodology aims to provide a comprehensive view of the main processes and activities involved in the integrated circuit industry. In particular, because the transistor is by far the most used electronic device and the one that appears in the largest number of contexts, it is used to illustrate how the learning resources, along with the flipped classroom, contribute to the construction of the mental models on how a real IC is built and operates.

The resources designed for this experience are presented in three inter-dependent knowledge blocks: "Technologies and processes", "Semiconductor devices" and "Specific tools and webinars" and they all contain learning resources and activities both pre-class and classroom time. Fig. 1 shows how before class and F2F activities are distributed, and which resources are used, respectively, to help students incorporate that information to their own model of the transistor. Also, it shows a key distinction between the resources that are presented to students both in before-class and F2F activities to provide guidance for different topics, and the resources designed to assess the degree of understanding of the topics, and in particular, the degree of construction of the models.

The following paragraphs present a description of the implementation of the different learning supporting materials, particularized for the topic of the MOS transistor:

- Webinars: Students are asked to attend to some sessions organizes as online seminars that deal with different aspects of the fabrication, operation and application of MOS transistors.

- Applets: Students get familiar with the physical and chemical processes that are carried out to fabricate MOS transistors: how masks are used to define active areas and how processes such as implantation, diffusion, or etching create them; and also about their operation, for which students can change the parameters that control each process. Fig. 2 illustrates this, in terms of the structure of the MOS transistor and its operation. With the help of the applets, students visualize the physical structure of an MOS transistor, creating a link with its behaviour.

- Simulation tools: Students characterize a single-stage amplifier formed by one MOS transistor, which is done in the classroom session in a collaborative way, divided in two stages. First, every student studies how the variation of one variable affects the general behaviour of the amplifier (both theoretically and by simulations). Then, they explain to the rest how the variable they have studied influences the amplifier behaviour, and all of them together have to make the decision (also using simulations) about which are the most suitable values for each variable. This is done in groups of three or four students. With this activity, students can evaluate the correctness of analytical solutions obtained using approximations and identify possible improvements, a usual procedure to create new models in science. 


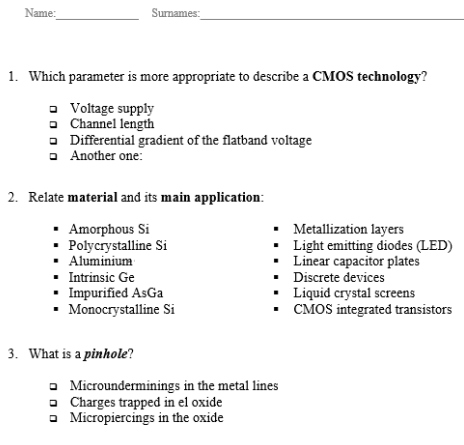

(a)

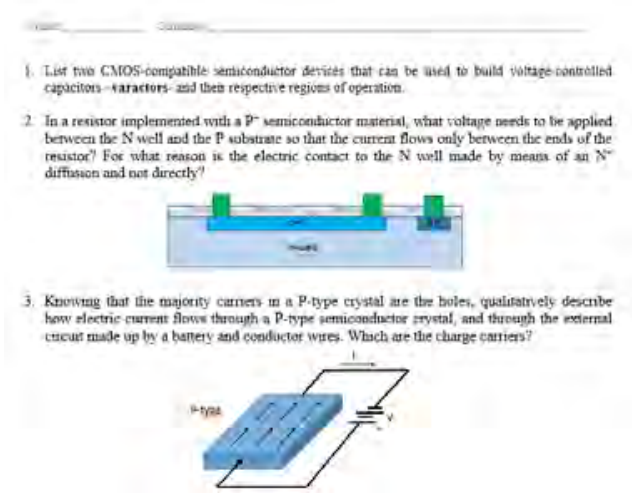

(b)

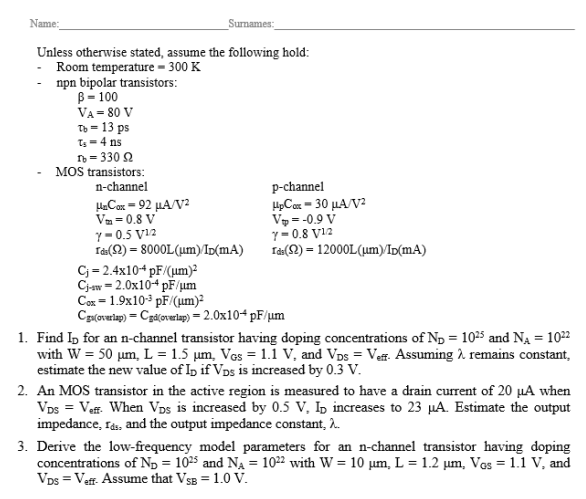

(c)

Fig. 3. Examples of the quiz-type activities proposed to students for the different learning activities planned throughout the course: (a) for the webinar sessions, (b) to be used collectively in F2F theoretical sessions, and (c) for the problem activities.

- Virtual laboratory: The use of simulation tools allows recreating the activities that are carried out in a laboratory session, where students need to assemble different test set-ups to perform the characterization of MOS transistors. Students are asked to write a scientific report containing not only a description of the work that has been done and the results obtained, but also a general state-of-the-art description, a motivation, and a discussion of the results. Students form groups of two to three people, which fosters the exchange of ideas and contributes to the construction of their models by contrasting and comparing them to those of their peers.

- Problem-based learning (PBL) sessions: Associated to before-class lectures, problems are designed as academic exercises where students are asked to apply their theoretical knowledge to different cases of the operation of MOS transistors. Problems, owing to their ideal nature, allow to focus on specific relevant aspects while neglecting others, so that by their design, particular theoretical aspects can be exercised, contributing to strengthening them in the construction of the mental models.

Every activity is designed to evaluate specific competencies and processes, which in turn translates into complementary relevant information to assess the construction of the mental models. The assessment of the topic "MOS transistor" will be done using the different knowledge and model assessment materials shown in Fig. 1: quizzes, problems and reports, and also a rubric to assess the practical realization of laboratory sessions. They are shown in Fig. 3.

Finally, a survey will be carried out at the end of the course to gather student feedback on the activity. Students will be asked about the teaching resources designed for this activity, both in terms of their own work and their autonomous learning, as well as about the concrete benefit that the flipped classroom strategy has on the understanding of the topics.

\section{DISCUSSION AND CONCLUSIONS}

This work presents the use of flipped classrooms as a pedagogical tool to implement model-based learning in higher education. A set of specific teaching resources, following a flipped classroom strategy, has been designed to enhance the construction of mental models by students of Electronics. The resources also serve to evaluate the models and to assess the effectiveness of the model-based learning approach. To the authors' knowledge, the flipped classroom has not been reported as a pedagogical strategy to help students in higher education with the construction of their knowledge models.

The flipped classroom strategy has been combined with other active methodologies and traditional lessons, choosing at each time the one that is more relevant and adequate for the students to comprehend each topic. This has advantages over the traditional approach such as increased student motivation and autonomy, or a deeper understanding of difficult concepts. The flipped classroom allows more time for active learning to happen in the classroom, and the teacher can follow the learning process more effectively.

In this respect, non-interactive resources are better suited to present the main topics and ideas, while interactive resources are useful to create links between them to build the models, and to check whether the conclusions drawn from the models are true. Students engage in a process where they develop their mental models with tools that facilitate their construction and also assess their correctness. This process requires the implication of every student and therefore fosters their learning autonomy, but also the exchange and social cooperation with their peers to analyse their own knowledge models, which entails sharing hypotheses, amending their thoughts and working with their cognitive disagreements.

\section{ACKNOWLEDGEMENTS}

This work has been partially supported by the Universidad de Zaragoza under grants PIIDUZ_17_065, PIIDUZ_15_001, and PIIDUZ_14_021. The authors would like to thank the BEAGLE research group (Universidad de Zaragoza) for their assistance in this work.

\section{REFERENCES}

[1] A. Kirkwood and L. Price, "Learners and learning in the twentyfirst century: what do we know about students' attitudes towards and 
experiences of information and communication technologies that will help us design courses?" Studies in Higher Education, vol. 30, no. 3, pp. 257-274, 2005.

[2] J. D. Gobert and B. C. Buckley, "Introduction to model-based teaching and learning in science education," International Journal of Science Education, vol. 22, no. 9, pp. 891-894, 2000.

[3] S. W. Gilbert, "Model building and a definition of science," Journal of Research in Science Teaching, vol. 28, no. 1, pp. 73-79, 1991.

[4] A. Harrison and D. Treagust, "A typology of school science models," International Journal of Science Education, vol. 22, no. 9, pp. 10111026, 2000.

[5] I. Halloun, "Mediated modelling in science education," Science Education, vol. 16, no. 7, pp. 653-697, 2007.

[6] J. Lopes and N. Costa, "The evaluation of modelling competences: difficulties and potentials for the learning of the sciences," International Journal of Science Education, vol. 29, pp. 911-951, 2007.

[7] G. Prins, A. Bulte, J. V. Driel, and A. Pilot, "Students' involvement in authentic modelling practices as contexts in chemistry education," Research in Science Education, vol. 39, no. 5, pp. 681-700, 2009.

[8] L. Barsalou, "Perceptual symbol systems," Behavioral and Brain Sciences, vol. 21, pp. 577-609, 1999.

[9] N. Nersessian, "Maxwell and "the method of physical analogy": Modelbased reasoning, generic abstraction, and conceptual change," Essays in the History and Philosophy os Science and Mathematics, pp. 129-166, 2002.

[10] R. Justi and J. Gilbert, "Modelling teachers views on the nature of modelling, and implications for the education of modellers," International Journal of Science Education, vol. 24, no. 4, pp. 369-387, 2002.

[11] M. B. Gilboy, S. Heinerichs, and G. Pazzaglia, "Enhancing student engagement using the flipped classroom," Journal of nutrition education and behavior, vol. 47, no. 1, pp. 109-114, 2015.

[12] L. Deslauriers, E. Schelew, and C. Wieman, "Improved learning in a large-enrollment physics class," science, vol. 332, no. 6031, pp. 862$864,2011$.

[13] N. Aronson, K. M. Arfstrom, and K. Tam, "Flipped learning in higher education," 2013.

[14] J. O'Flaherty and C. Phillips, "The use of flipped classrooms in higher education: A scoping review," The Internet and Higher Education, vol. 25, pp. 85-95, 2015.

[15] Y. Chen, Y. Wang, Kinshuk, and N.-S. Chen, "Is FLIP enough? or should we use the FLIPPED model instead?" Computers \& Education, vol. 79 pp. 16-27, 2014.

[16] R. Pierce, J. Fox, and B. Dunn, "Instructional design and assessment: Vodcasts and activelearning exercises in a "flipped classroom" model of a renal pharmacotherapy module," American Journal of Pharmaceutical Education, vol. 76, no. 10, pp. 1-5, 2012.

[17] A. K. Wood, R. K. Galloway, R. Donnelly, and J. Hardy, "Characterizing interactive engagement activities in a flipped introductory physics class," Phys. Rev. Phys. Educ. Res., vol. 12, p. 010140, 2016.

[18] J. Jovanović, D. Gaŝević, S. Dawson, A. Pardo, and N. Mirriahi, "Learning analytics to unveil learning strategies in a flipped classroom," The Internet and Higher Education, vol. 33, pp. 74-85, 2017.

[19] H.-L. Chen and C.-Y. Chang, "Integrating the SOP' model into the flipped classroom to foster cognitive presence and learning achievements," Journal of Educational Technology \& Society, vol. 20, no. 1, pp. 274-291, 2017.

[20] G.-J. Hwang and C.-L. Lai, "Facilitating and bridging out-of-class and in-class learning: An interactive e-book-based flipped learning approach for math courses," Journal of Educational Technology \& Society, vol. 20, no. 1, pp. 184-197, 2017.

[21] J. Bergmann and A. Sams, Flip your classroom: Reach every student in every class every day. International Society for Technology in Education, 2012.

[22] P. Baepler, J. Walker, and M. Driessen, "It's not about seat time: Blending, flipping, and efficiency in active learning classrooms," Computers \& Education, vol. 78, pp. 227-236, 2014.

[23] K. Miller, S. Zyto, D. Karger, J. Yoo, and E. Mazur, "Analysis of student engagement in an online annotation system in the context of a flipped introductory physics class," Phys. Rev. Phys. Educ. Res., vol. 12, p. 020143, 2016.

[24] C. Sánchez-Azqueta, C. Gimeno, S. Celma, and C. Aldea, "Using the Wiimote to learn MEMS in a Physics Degree program," IEEE Transactions on Education, vol. 59, no. 3, pp. 169-174, 2016.
[25] Ünal Çakiroglu and M. Öztürk, "Flipped classroom with problem based activities: Exploring self-regulated learning in a programming language course," Journal of Educational Technology \& Society, vol. 20, no. 1, pp. 337-349, 2017.

[26] A. Sivan, R. W. Leung, C.-c. Woon, and D. Kember, "An implementation of active learning and its effect on the quality of student learning," Innovations in Education and Teaching International, vol. 37, no. 4, pp. 381-389, 2000.

[27] S. Dimitrijev, Understanding semiconductor devices. Oxford University Press on Demand, 2000, vol. 1.

[28] C. Sánchez-Azqueta, C. Gimeno, S. Celma, and C. Aldea, "Applets for physical electronics learning," in XI Technologies Applied to Electronics Teaching (TAEE 2014), 2014, pp. 1-5.

[29] I. Cadence Design Systems, http://www.cadence.com/, online: accessed 23-June-2018.

[30] F. Dochy, M. Segers, and D. Sluijsmans, "The use of self-, peer and coassessment in higher education: A review," Studies in Higher education, vol. 24, no. 3, pp. 331-350, 1999.

[31] C. Sánchez-Azqueta, C. Gimeno, C. Aldea, and S. Celma, "E-learning data base for a Wiki-MEMS," in International Congress on Education, Innovation and Learning Technologies (ICEILT 2014), 2014, p. 28. 